\title{
Experimental study on evaporation, condensation and production of a new tubular solar still
}

\begin{abstract}
This paper describes a comparison between our first model of a Tubular Solar Still (TSS) and a second one. The first model was designed by our research group using a vinyl chloride sheet as a transparent tubular cover. Since then, we have designed the second model that has improved the assembly, economy and maintenance over the first model. In the second model, a polythene film was adopted as the cover. As a result, the cover weight and cost of the second model were noticeably reduced and the durability was distinctly increased. A set of laboratory experiments was carried out using a special technique to investigate the evaporation, condensation and distilled water production performance independently and simultaneously on the second model. It was revealed that the hourly evaporation, condensation and production fluxes were proportional to the humid air temperature and relative humidity fraction. Consequently, an empirical equation was proposed based on this relation to predict the hourly production flux. The applicability of this equation was examined from the comparison with field experiments in Fukui, Japan and in Ras Al Khaimah, UAE. It was seen that the calculated results had a good agreement with the field data.
\end{abstract}

Keyword: Evaporation; Condensation; Production; Tubular solar still (TSS); Humid air 